\title{
An ontogenetic perspective on migratory strategy of a long-lived pelagic seabird: Timings and destinations change progressively during maturation
}

\author{
Letizia Campioni $^{1}$ (D) | Maria Peixe Dias ${ }^{1,2}$ (D) | José Pedro Granadeiro ${ }^{3}$ (D) | \\ Paulo Catry ${ }^{1}$
}

${ }^{1}$ MARE - Marine and Environmental Sciences Center, ISPA - Instituto Universitário, Lisboa, Portugal

${ }^{2}$ Birdlife International, Cambridge, UK

${ }^{3}$ Departamento de Biologia Animal, CESAM, Faculdade de Ciências da

Universidade de Lisboa, Lisboa, Portugal

Correspondence

Letizia Campioni

Email: letiziacampioni@hotmail.com

Funding information

Fundação para a Ciência e a Tecnologia

Handling Editor: Annette Fayet

\begin{abstract}
1. The processes that drive the ontogeny of migratory strategies in long-lived animals with slow maturation remain enigmatic. While some short-lived migrants are known or believed to repeat the same migratory patterns throughout their lives, little is known on the time required for immature long-lived migrants to progressively acquire adult-like migratory behaviours, or which aspects take longer to refine during the maturation process.
\end{abstract}

2. Here, we studied the ontogeny of long-distance migratory strategies and related patterns of spatial distribution in a long-lived seabird species during the annual cycle. To do so, we deployed light-level geolocators on 4- to 9-year-old immature Cory's shearwaters (Calonectris borealis) and on breeding adults.

3. We revealed that migratory timings and destinations of young shearwaters progressively changed with age. The effect of ageing was remarkably evident on spring migratory performance and phenology. Birds gradually shortened the duration of the non-breeding period by advancing departure date and reducing travelling time, which resulted in a sequential arrival at the colony of the various age contingents. Ageing immatures gradually changed from a more exploratory strategy to a more conservative way of exploiting resources, reducing both their year-round spatial spread across oceanic domains and the total distance travelled. Immatures always performed a trans-equatorial migration to the Southern Hemisphere, contrasting with $17 \%$ of the adults which remained in the North Atlantic year-round. Finally, during the breeding season immatures were widely dispersed through the North Atlantic reducing their overlap with breeding adults.

4. Our long-term study provides empirical support to the hypothesis that in longlived species, the refinement of migratory behaviour and year-round spatial distribution is a progressive process mediated by age and experience, where life stage constraints and competition for resources may also play a role. The emerging pattern suggests that for some avian taxa, the ontogeny of migratory strategy is a prolonged, complex and dynamic process. 


\section{KEYWORDS}

biologging, experience, geolocation, immature bird, long-distance migration, pelagic seabirds, spatial distribution

\section{1 | INTRODUCTION}

The adaptive changes of behaviour based on past experience, namely learning (Dukas, 2004; Shettleworth, 1999), affect virtually every aspect of animal behaviour with potential fitness implications (Brown, Bomberger Brown, \& Brazeal, 2008; Raine \& Chittka, 2008). For example, in iteroparous species, the reproductive performance of young age classes typically improves as individuals age and gain experience (Clutton-Brock, 1988; Forslund \& Pärt, 1995; Newton, 1989; Pärt, 1995). Similarly, in long-lived animals with slow maturation, differences in foraging skills and efficiency between adults and naïve young individuals are generally ascribed to the lack of experience of the latter (Daunt, Afanasyev, Adam, Croxall, \& Wanless, 2007; Fayet et al., 2015; Le Vaillant et al., 2012; Lefebvre, 1995; Zimmer, Ropert-Coudert, Kato, Ancel, \& Chiaradia, 2011). Such observations support the idea of a progressive ontogenetic shift in feeding ecology (Carravieri, Weimerskirch, Bustamante, \& Cherel, 2017) and behaviour (Votier et al., 2017). This paradigm has also been applied to explain changes observed in a diversity of movement strategies, in space use behaviour and in locomotion performance (Yoda, Kohno, \& Naito, 2004) in species with an extended maturation phase (Hays, Fossette, Katselidis, Mariani, \& Schofield, 2010; Penteriani, Delgado, \& Campioni, 2015; RiotteLambert \& Weimerskirch, 2013; Sergio et al., 2014). It is during this phase that inexperienced individuals are expected to develop and tune up the abilities needed to navigate and orient themselves during long-distance movements (Alerstam, Hedenstrom, \& Akesson, 2003; Orben et al., 2018; Thorup, Alerstam, Hake, \& Kjellén, 2003; Yoda et al., 2017) or to learn how to keep track of time as they exploit geographically distant resources (Åkesson et al., 2017; Strandberg et al., 2008). Under this scenario, immatures are also believed to show greater inter- and intra-individual variability in space use, compared to older conspecifics which have already gained familiarity with the spatial distribution of resources or for example, with migratory routes (de Grissac, Börger, Guitteaud, \& Weimerskirch, 2016; Sergio et al., 2014; Votier et al., 2017; Wakefield et al., 2015).

In migratory taxa, the choice of and fidelity to travel routes, stopovers and non-breeding destinations suggest that the migratory lifestyle has influenced the long-term learning and memorizing capacities of some long-distance bird species (Fagan et al., 2013; Mettke-Hofmann \& Gwinner, 2003; Vardanis, Klaassen, Strandberg, \& Alerstam, 2011). However, to date there are only few examples of the cumulative effect of experience and spatial learning in refining lifelong migratory strategies or fidelity to specific areas (e.g. non-breeding destination) in terrestrial bird species (Milvus migrans; Sergio et al., 2014) or in seabirds (Diomedea exulans; Lecomte et al.,
2010; Riotte-Lambert \& Weimerskirch, 2013; Weimerskirch et al., 2014). Recent studies revealed patterns consistent with "exploration-refinement" mechanism in two long-lived seabirds, the Atlantic puffin, Fratercula arctica (Guilford et al., 2011), and the northern gannet, Morus bassanus (Votier et al., 2017), suggesting that inter-individual differences in migratory behaviour and progressive foraging site specialization due to learning may represent a common component in species living relatively long lives.

Intraspecific competition for resources (Breed, Bowen, \& Leonard, 2013) may represent an alternative mechanism responsible for age-specific movement strategies, as it promotes spatial niche differentiation in ecologically similar animals with different competitive abilities (Webb, Marzluff, \& Hepinstall-Cymerman, 2012). For example, in the marine ecosystem, seabirds often suffer from intraspecific competition either in proximity to their colony (i.e. breeding season) or in the distant non-breeding quarters (i.e. inter-breeding season; Fayet et al., 2017; Lamb, Satgé, \& Jodice, 2017). According to the nature and persistence of such competition, individuals might space out in order to mitigate its effect (Thiebot, Cherel, Trathan, \& Bost, 2012). Under this scenario, distributions might be expected to show spatio-temporal segregation, with younger and subdominant conspecifics likely performing alternative foraging and/or migratory strategies.

Cory's shearwater, Calonectris borealis, is a medium-sized petrel species that exhibits a flexible migratory strategy with individuals being generally site-faithful, but with regular, even if less common, changes in non-breeding destinations across the Atlantic Ocean. The migratory strategies and non-breeding distribution of adults are well studied (Dell' Ariccia et al., 2018; Dias, Granadeiro, \& Catry, 2012, 2013; Dias, Granadeiro, Phillips, Alonso, \& Catry, 2011; GonzálezSolís, Croxall, Oro, \& Ruiz, 2007), and for that reason, the species is particularly suitable as a model to establish comparisons among age classes in migratory strategies. Young Cory's shearwaters start to attend their natal colonies in the North-East Atlantic Ocean at the age of 4 years, albeit postponing the time of first breeding up to the mean age of nine (Mougin, Jouanin, \& Roux, 2000).

Here, we used light-level geolocators to study the ontogeny of long-distance migratory strategies and related patterns of spatial distribution of 4- to 9-year-old immature and adult Cory's shearwaters during the annual cycle. If immatures gradually shift migratory timings, stopovers and destinations converging to resemble those of breeding adults, this would support the hypothesis of a progressive change in migratory strategies and space use mediated by age and experience (Sergio et al., 2014) and perhaps competitive interactions (Fayet et al., 2017). Alternatively, if immatures' migratory behaviour precociously resembles that of adults, this would suggest a mechanism where after a first migration largely driven 
by an innate programme (Vansteelant, Kekkonen, \& Byholm, 2017) the birds repeat the same pattern of movement between generally fixed breeding and wintering areas (Cresswell, 2014; Yamamoto et al., 2014).

\section{2 | MATERIALS AND METHODS}

\section{1 | Study site and tracked birds}

Fieldwork was carried out at Selvagem Grande Island $\left(30^{\circ} 09^{\prime} \mathrm{N}\right.$, $15^{\circ} 52^{\prime} \mathrm{W}$ ) in the North-East Atlantic Ocean, which hosts the world largest population of Cory's shearwater, Calonectris borealis (ca. 30,000 breeding pairs, Granadeiro, Dias, Rebelo, Santos, \& Catry, 2006). Since 2004 the Cory's shearwater colony on Selvagem Grande has been the focus of a long-term monitoring study where breeders and chicks have been systematically ringed and demographic and reproductive data recorded (Granadeiro et al., 2006). During each breeding season from early incubation (15 June) to the mid-chick-rearing (15 August) we carried out extensive systematic visits to the study areas, recording the presence and reproductive status of all birds attending the study plots. Due to the high nest-site fidelity, most birds breeding in the study plots have been ringed during the course of the long-term study, and every year, new recruits to the colony are ringed or controlled (if ringed as chicks from previous years) when they start nesting. On the basis of this control, we were able to distinguish between breeding adults (individuals incubating an egg) and immature birds (individuals that have never reproduced before). Because immature birds were ringed as chicks we could infer their ages from date of ringing. We deployed leg-mounted geolocators (hereafter GLS; mk7 and mk19 models developed by British Antarctic Survey) on 4- to 9-year-old immatures and successful breeding adults (active breeders successfully raising a chick). Geolocators weighed 2.5$3.6 \mathrm{~g}$ (corresponding to less than $0.5 \%$ of the weight of the birds, considering an average bird weight of $800 \mathrm{~g}$; Ramos, Granadeiro, Phillips, \& Catry, 2009). Geolocators were deployed at the end of each breeding season (August/September) and recovered in the subsequent breeding seasons (from April to August). Among immatures (seven females, 25 males and five birds of unknown sex) thirteen birds were tracked more than once (eight birds during two seasons, four during three seasons and one during four seasons). Among adult breeders (35 females and 46 males), twenty-one birds were tracked more than once (sixteen were tracked during two seasons, four birds during three seasons and one during five seasons). Over the 8-year study period, we gathered data from 108 and 56 complete migrations of adult breeders and immatures, respectively (2007/2008: $n=22+1 ; 2008 / 2009: n=22+1$; 2010/2011: $n=20+19 ; 2011 / 2012: n=11+11 ; 2012 / 2013$; $n=12+5 ; 2013 / 2014: n=8+11 ; 2014 / 2015: n=13+6$, 2015/2016: $0+2)$.

Cory's shearwaters were sexed employing a combination of two different methods: (a) based on their distinctive vocalizations (three immatures in combination with method (b); Thibault, Bretagnolle, \& Rabouam, 1997) and (b) by means of a discriminant function based on bill measurements (all birds; Granadeiro, 1993). By using these two criteria, and cross-validating with nesting partners (all breeding adults and 13 immatures), sex classification accuracy was $>99 \%$ (Pérez, Granadeiro, Dias, Alonso, \& Catry, 2013). Finally, for $31 \%$ of immatures $\left(n_{\text {tot }}=37\right)$ where the discriminant function did not allow a high confidence in sexing, we employed molecular procedures using DNA extracted from blood samples (Griffiths, Double, Orr, \& Dawson, 1998).

\section{2 | Geolocation data processing}

Geolocators provide two positions per day based on levels of ambient light with an accuracy of approximately $200 \mathrm{~km}$ (Phillips, Silk, Croxall, Afanasyev, \& Briggs, 2004). Light data were analysed using TransEdit (to check for integrity of light curves and to determine dawn and dusk times) and BIRDTRACK software (to estimate the latitude from day length and longitude from the time of local midday relative to Greenwich Mean Time). The sun elevation angle parameter was set to vary between $-2.5^{\circ}$ and $-4.5^{\circ}$, based on known positions obtained during ground-truthing of each logger, carried out before each deployment or after each recovery. Unrealistic positions (those resulting from interference with light curves at dawn or dusk or those around equinox periods ( \pm 21 days); Phillips et al., 2004) were removed from the general analysis. The final part of the return migration of many Cory's shearwaters coincides with spring equinox. Hence, for example, the dates of arrival at the colony were estimated on the basis of longitude data, which are not affected by the proximity to the equinox (see Dias et al., 2011).

\section{3 | Phenology and characteristics of migration}

For each migration event we estimated a set of date parameters, corresponding to movements relative to a set of specific landmarks: (a) departure from the colony: birds leave a buffer of $200 \mathrm{~km}$ radius centred on Selvagem Grande, (b) departure from the Canary Current: when birds cross the meridian 18W, (c) birds crossing parallel $10 \mathrm{~N}$, (d) birds crossing meridian $10 \mathrm{E}$ once in the Southern Hemisphere and (e) arrival at the main non-breeding ground that is, when consecutive locations stabilize in an area (see Figure S1). After departing from the non-breeding ground and for the pre-breeding journey we estimated (f) departure date from the non-breeding ground defined as the onset of a clear northward directional movement and (g) the arrival date at colony estimated as the day in which longitude values approximate that of Selvagem Grande with birds showing a clear (eastward) variation as they approach the colony (see Dias et al., 2011). Finally, (h) arrival date at the nest was also estimated as the first day when there was no light record during daytime after the arrival at the colony. Moreover, we estimated the duration of both pre-breeding migration (i.e. the difference between arrival time at colony 
and departure date from non-breeding ground) and post-breeding journey (i.e. the difference between arrival time at non-breeding ground and departure from Canary Current). The time spent in the main non-breeding area was calculated as the difference between departure and arrival date from/to non-breeding ground. Finally, we identified the main non-breeding destination as the area where a bird spent the largest amount of time, once outside the Canary Current (i.e. after crossing the $18 \mathrm{~W}$ meridian). When individuals had multiple stopover sites, we identified/distinguished the main stopover site by a visit of at least 15 days (i.e. enough time to familiarize with the place and equal to the minimum time period spent by birds in the main non-breeding area). For each individual we calculated a proxy for the year-round distance travelled (September-August) as the sum of absolute difference (in degrees of longitude) between consecutive longitude values divided by the number of tracking days and multiplied by 365 days. Similarly, we calculated a proxy for distance travelled during the non-breeding period (September-May) by removing longitude values from June to August (when breeders are engaged in breeding duties, thus less mobile). We also calculated a proxy of pre-breeding migration speed as the sum of absolute difference (in degrees of longitude) between consecutive longitude values between departure from non-breeding grounds and arrival date at the colony divided by pre-breeding migration duration (in days). Similarly, we estimated the post-breeding migration speed based on the mean travelling speed calculated between departure from colony and arrival to the main wintering ground. Moreover, we emphasize that the approach we used to approximate the distance travelled by immature birds is used in a comparative context and it cannot provide an absolute estimate of the real distance travelled although the cumulative variations in longitude values is well correlated with the "true" distance travelled (see Figure S2 for more details).

\section{4 | Spatial distribution data}

We estimated spatial diversity in the (annual) distribution of immatures using an adapted version of the Shannon-Wiener index:

$$
D I(x)=-\sum_{n=1}^{m}[p(x) * \ln p(x)]
$$

where $D I(x)$ is the distribution diversity index for the bird $x$ and $p(x)$ is the proportion of the number of days spent in each of the six oceanic regions $(m)$ identified as the main Cory's shearwater nonbreeding areas (Dias et al., 2011; Figure S3). Locations between 20 March \pm 21 days and 23 September \pm 21 days which correspond to the equinox periods ( \pm 21 days), were not included (see the subsection Geolocation data processing for more details). A minimum number of 130 days of data per individual was set as the inclusion threshold for analysis.

We compared the spatial extent of the summer distribution (July-September) of 4- to 6-year-old immature birds and of 7- to 9-year-old immature birds with those of breeding adults. To do this, we superimposed a grid of $1 \times 1$ (degree) cells on a map of the North Atlantic Ocean (WGS 84) and we randomly selected 20 locations from an increasing number of individuals and counted the total number of occupied cells for each age group, that is 4to 6-year-old birds, 7- to 9-year-old immature birds and breeding adults. We estimated the $95 \%$ confidence interval of the estimates (median) as the 0.025 and 0.975 quantiles.

\section{5 | Data analysis}

We investigated the relationship between age and migration phenology (departure date from the colony and Canary Current, crossing time of parallel $10 \mathrm{~N}$ and meridian $10 \mathrm{E}$, arrival and departure times at/from non-breeding area, arrival date at the colony and nest, duration of pre- and post-breeding migration and length of stay on the main non-breeding area) by employing linear mixed models (LMMs). The effect of age as an explanatory variable was explored as a polynomial function up to the quadratic order (allowing the investigation of nonlinear variation in timing of migration with age, including inversion of trends). In a few cases the effect of age was tested by grouping immatures into two age classes, namely birds aged 4-6 years and 7-9 years (hereafter age classes), and then compared to adult breeders. Grouping was done to ensure for adequate sample sizes when no age-related differences were found among immatures, thus enabling comparisons with adult breeders of unknown age. Because there were no sexor year-related differences in immature's migration timings (all $p>0.2$ ), all data were pooled together. In order to account for potential differences in migration phenology related to differences in non-breeding destinations (i.e. South America and Southern Africa), we repeated the same analysis including only birds overwintering in Southern Africa (presented in Results).

Similarly, we compared the pre- and post-breeding migration speed (migration length [sum of absolute difference between consecutive longitude values]/migration duration; the result is expressed in degree/day), after accounting for departure date, among immatures of different ages (from 4 to 9 years). Moreover, by using a generalized linear mixed model (GLMM) with binomial error structure $(0=$ not breeding after migration, 1 = breeding after migration) we tested whether individual age and arrival date at colony might influence the probability of recruiting into the breeding population (i.e. the probability of breeding for the first time, as opposed to attending the natal colony without engaging in a reproductive attempt where an egg was laid). Furthermore, we used LMMs to compare (year-round) spatial distribution diversity (DI), total distance travelled and distance travelled during the non-breeding period (excluding June-September) between different ages and breeding status.

In order to study the choice of non-breeding areas we randomly selected one migration event per each bird and first tested whether immatures and breeding adults were equally likely to spend the nonbreeding period in the Northern or Southern Hemisphere, using a Fisher's Exact Test. Second, because Southern Africa (Agulhas and Benguela currents) was the main non-breeding region of immatures $(89.2 \%, n=56)$ and breeding adults $(51 \%, n=112)$, we further 
investigated the probability of overwintering in Agulhas $(p=1)$ or Benguela $(p=0)$ Current areas using a general linear model (GLM; binomial error structure) with age classes (4- to 6-year-old immatures, 7- to 9-year-old immature birds and breeding adults) as a covariate. However, because immatures sample size was skewed towards males (seven females, 25 males, five unknown sex; $\chi^{2}=9.36, d f=1$, $p=0.0025)$ and because wintering area choice by breeding adults can be sex-biased (Pérez et al., 2013), females and birds with unknown sex were removed from this analysis.

Moreover, because the North-West Atlantic resulted to be the main stopover site, we investigated the probability of using that area in relation to bird age (GLM, binomial error structure). To investigate the fidelity of birds to the non-breeding destination, we modelled the probability of switching between non-breeding destinations (i.e. Brazilian Current, Central South Atlantic area, Benguela Current and Agulhas Current) in consecutive years. To do that, we selected individuals with at least two migration journeys and fitted a GLMM (binomial error structure) with breeding status (i.e. breeding adult vs. immature) as an explanatory variable.

We recorded more than one migratory journey from some individuals, and therefore, we used bird identity (ID) as a random effect in the above mentioned analyses. Finally, model selection was performed using likelihood ratio tests ( $F$ or $\chi^{2}$ as test statistic, LRT) where a full model and nested models were compared (Zuur, Ieno, Walker, Saveliev, \& Smith, 2009). Whenever the explanatory variables showed nonlinear relationships with the response variable, logarithmic or square-root transformations were applied. Also, sample sizes for each analysis varied according to the available information for each particular bird migratory journey. We used model diagnostic plots to validate model results (Faraway, 2006). All analyses were performed using the software R 3.3.0 ( $R$ Core Team, 2016).

\section{3 | RESULTS}

We analysed 164 migratory tracks of which 56 from 37 immature Cory's shearwaters (age 4-9 years) and 108 from 81 adult breeders (Table 1 and Table S1, Figures 1 and 2). Immatures of different ages migrating to Southern Africa $(89.2 \%, N=56)$ did not show any difference in departure dates from colony and Canary Current (likelihood ratio test: colony: $L R T=0.17, d f=1, p=0.7$; Canary Current: $L R T=1.5$, $d f=1, p=0.22$ ), neither in the crossing of geographic landmarks (parallel 10N: $L R T=1.5, d f=1, p=0.21$; meridian $10 \mathrm{E}: L R T=1.8, d f=1$, $p=0.18$; Table 1). Arrival time to the non-breeding area was similar between immatures of different ages $(L R T=1.62, d f=1, p=0.2)$ albeit older birds reduced the duration of the southwards journey (Table 2M1) and stopped over less frequently (Table 2-M7, Figure 2f).

When we compared only individuals overwintering in Southern Africa, thus accounting for potential differences in migratory destinations, we found that the length of stay on the non-breeding grounds shortened as immatures aged (Table 2-M3, Figure 2a), reflecting the progressive advancement of departure date from the non-breeding grounds with age (Table 2-M2, Figure 2a,c). The duration of the pre-breeding journey (Table 2-M6, Figure 2e) and the following arrival time at the colony (Table 2-M4, Figure $2 \mathrm{~b}, \mathrm{~d}$ ) were also age-dependent, with older immatures reducing travelling time and approaching the natal colony earlier as compared to younger peers. However, mean pre-breeding migration speed did not correlate with either departure date from the non-breeding area $(L R T=0.3, d f=1$, $p=0.60)$ or immatures' age ( $L R T=0.7, d f=1, p=0.41)$. This result is explained by the fact that migration distance decreased with age as well (Figure S4A). Conversely, the mean post-breeding migration speed was positively correlated with the departure date from the Canary Current, with a marginal effect of age (Table 2-M13), suggesting that birds departing late increased their mean travel speed. First-time breeders from any age class (6-9 years), namely immature birds that after a migration event bred for the first time in the study colony, arrived at the natal place significantly earlier than conspecifics equal in age which did not recruit (Table 2-M10). Overall, migratory timings of immature shearwaters shifted progressively towards those of adult breeders until the point of synchronizing with them (Table 1, Figure 2a,b). These results remain largely unchanged when comparing migratory timings of birds travelling to/from different non-breeding destinations (Table S1).

The non-breeding spatial distributions of both immatures and adult breeders between the Southern versus Northern Hemisphere were broadly similar except for the use of two areas in the North Atlantic Ocean ( $p=0.023$, Fisher's exact test; Figure 3). No immatures used the Canary Current (adults used it $10.2 \%$ of cases, $N=108$ ) nor the North-West Atlantic (adults: $5.5 \%$ of cases) as main non-breeding destinations. However, immatures temporarily visited the North-West Atlantic ( $36 \%$ of the trips, $N=56$ ) mainly on their southwards journeys ( $>84 \%$ of cases), and more than breeding adults (8\%). The probability of using the North-West Atlantic as a stopover site decreased progressively with age (Table 2-M11). Immatures $(N=56)$ migrated to the Southern Hemisphere towards four main non-breeding destinations: the Brazilian Current (8.9\%), the Central South Atlantic area (1.9\%), the Benguela Current (44.6\%) and the Agulhas Current (44.6\%). Southern Africa was the most preferred non-breeding destination for all birds with males having a similar probability of overwintering in Agulhas or Benguela Current regardless of their age class ( $L R T=2.7, d f=2, p=027)$. In general, immatures were faithful to their main non-breeding destinations returning to the same area $87.2 \%$ of the time $\left(N_{\text {repeated journey }}=32\right)$, with breeding adults showing a similar rate $\left(82.3 \%, N_{\text {journey }}=47 ; L R T=0.81\right.$, $d f=1, p=0.37)$.

When we analysed the year-round movement behaviour of birds wintering around Southern Africa, immatures travelled longer distances (approximated as the sum of daily longitude variations; see Methods) in comparison to adult breeders (Table 2-M8). We obtained comparable results even when not considering periods corresponding to incubation and early chick-rearing, when adult breeders are expected to travel shortest distances (Table 2-M9). However, we did not find any difference in distance travelled by immatures in relation to their age $(L R T=0.58, d f=1, p=0.44)$. 


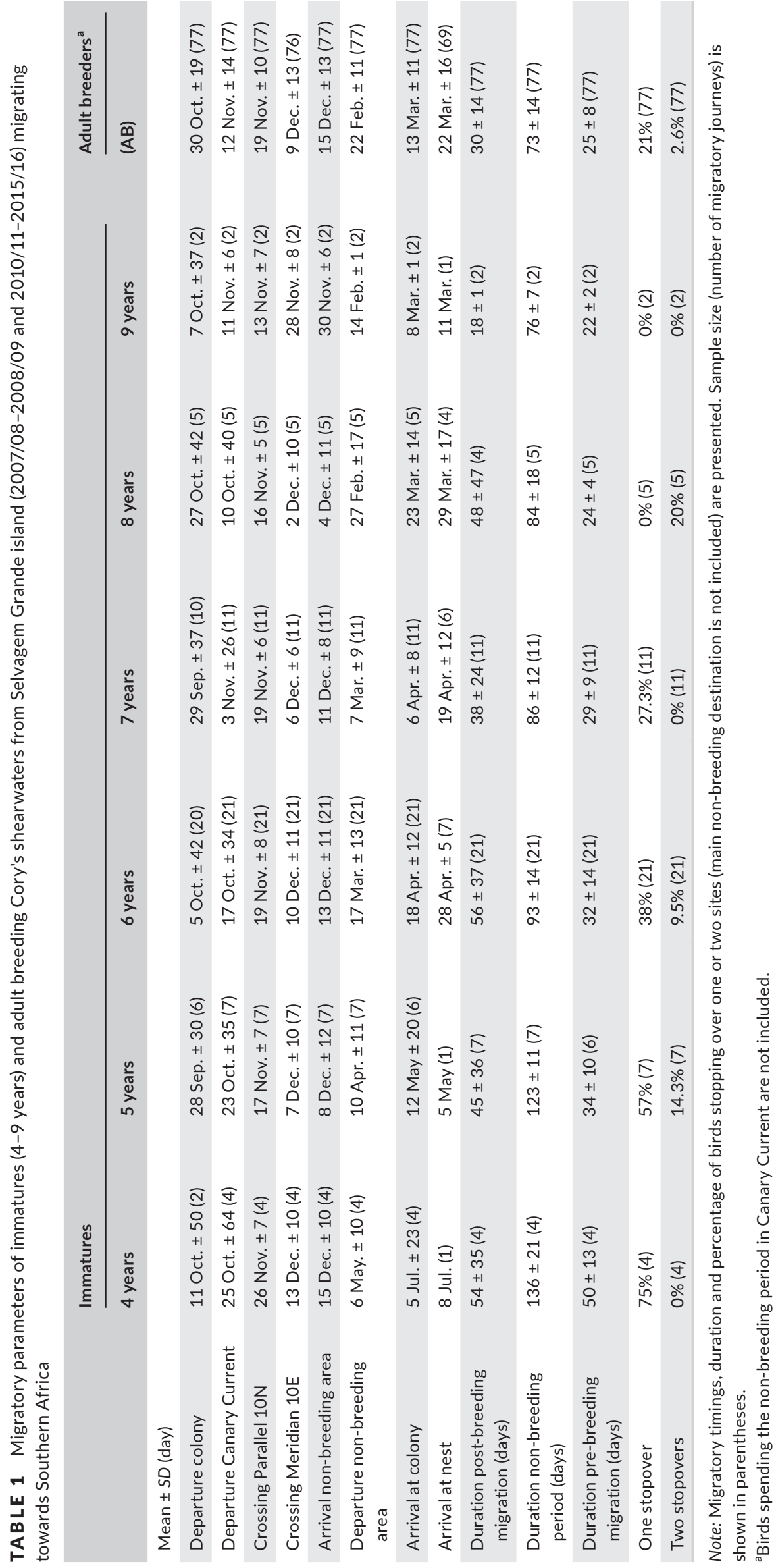


(b)
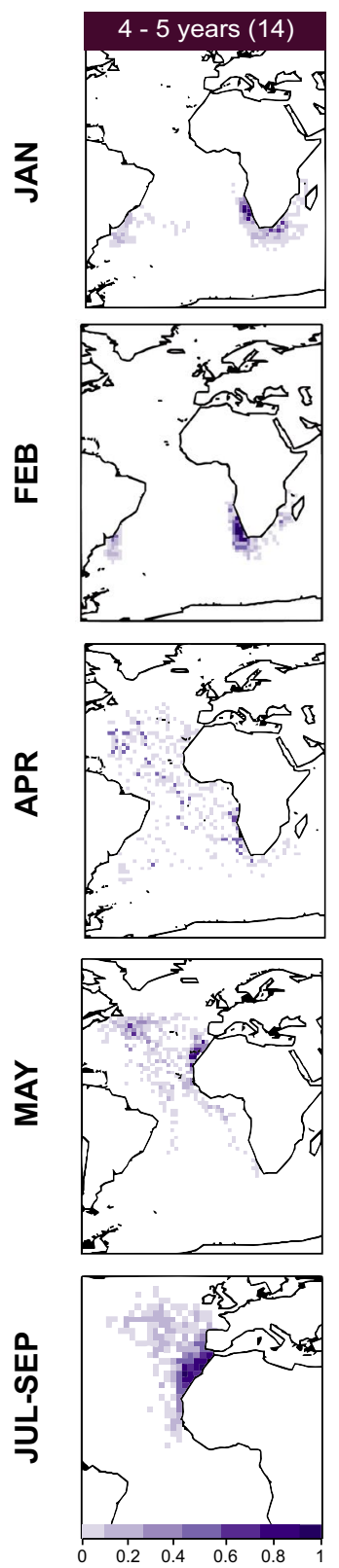

(a)
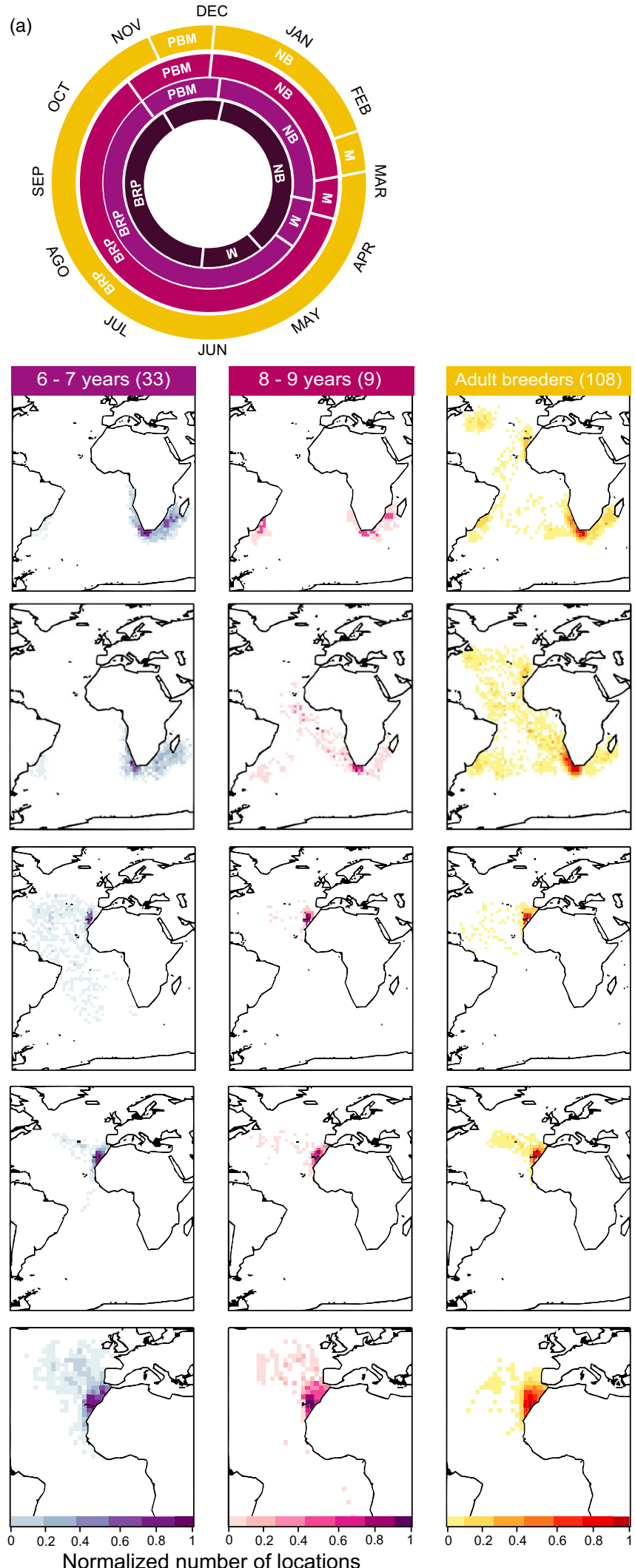

FIGURE 1 The annual-cycle schedules (a) of immatures and breeding adult Cory's shearwaters (BRP: breeding period; M: pre-breeding migration; NB: non-breeding period, PBM: post-breeding migration). (b) A selection of five snapshots is presented to show changes in migratory timings and distributions of Cory's shearwater according to age and breeding status (JAN: non-breeding period; FEB: adults' prebreeding migration; APR: immatures' pre-breeding migration; MAY: pre-laying period; JUL-SEP: breeding period). Data were scaled (Min-Max normalization of number of locations per $1 \times 1$ cell) to a fixed range of $0-1$. Number of migration events is shown in parentheses 

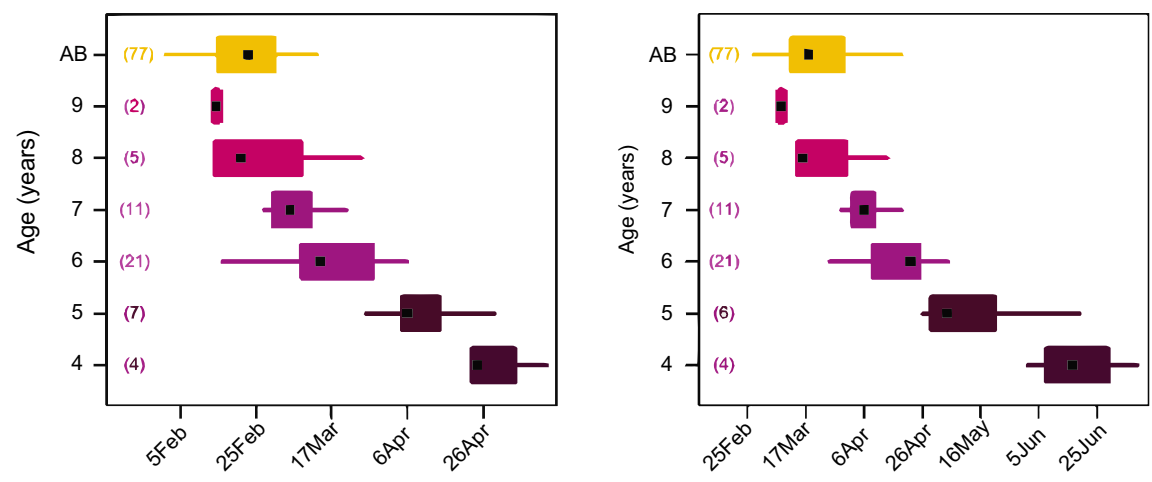

Departure date non-breeding area

Arrival date at colony
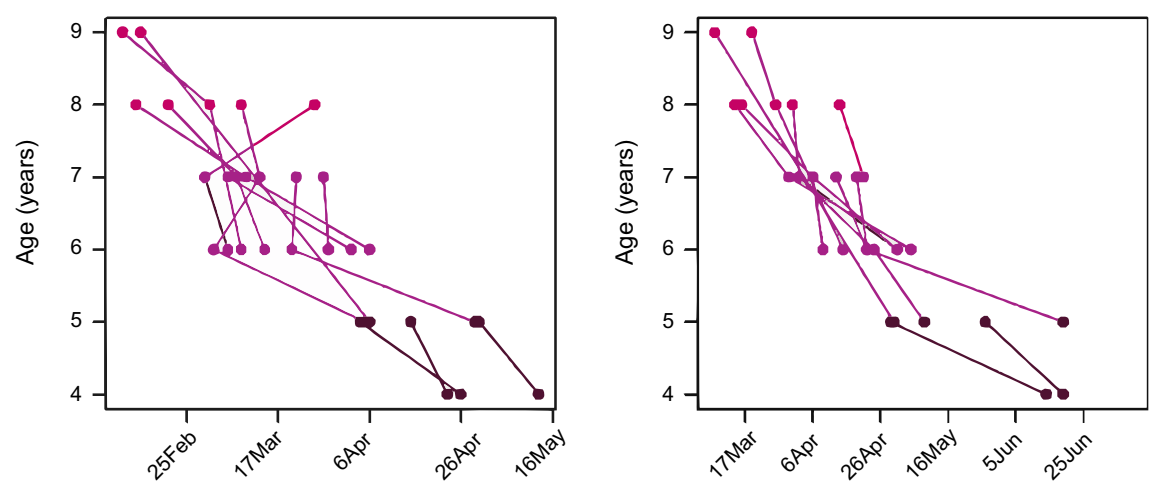

Departure date non-breeding area
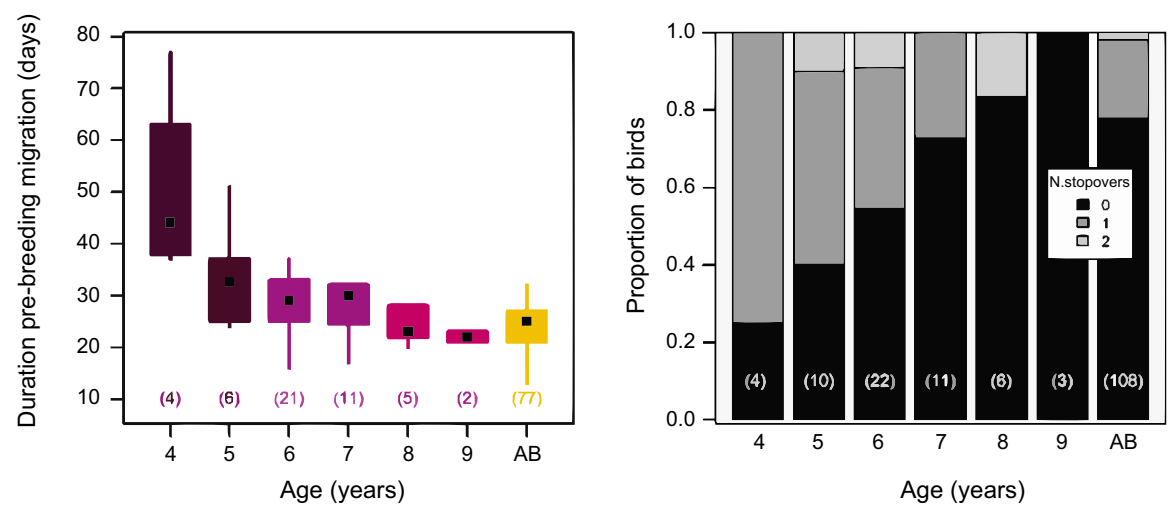

FIGURE 2 Plots showing changes in migratory timings and the number of visited areas (stopovers) of immature Cory's shearwaters from different age classes and of adult breeders (AB). (a) Sequential departures from Southern Africa non-breeding area and subsequent (b) arrival date at the colony. (c, d) Within-individual changes in departure date from the non-breeding area and arrival date at the colony of immatures with multiple migratory journeys ( $n=13$, eight birds during two seasons, four during three seasons and one during four seasons). Note how each individual follows the general population trend as it ages; (e) duration of pre-breeding migration of birds overwintering in Southern Africa; (f) proportion of birds using a different number of stopover sites regardless of their overwintering destination in relation to age. Stopovers are mostly used during the post-breeding migration journey

The diversity of the spatial distribution across the six oceanic macro-regions (DI) of immatures throughout the annual cycle declined as the birds aged (Table 2-M12, Figure 4a). When we narrowed the focus of the analysis to the breeding period (incubation and chick-rearing), we found that both 4- to 6-year-old immatures and 7- to 9-year-old immatures were more dispersed compared to breeding adults, occupying a higher number of grid cells of the North Atlantic (Figure 4b).

\section{4 | DISCUSSION}

This long-term study of known-age individuals revealed that the migratory behaviour of Cory's shearwaters changes progressively until approximately the mean age of first breeding, at 9 years old. This suggests a long process of learning and refinement, rather than the simple running of a migratory programme that repeats itself through the life of individual birds. 
TABLE 2 Summary of models used to investigate the variation in the migratory strategy of immature Cory's shearwaters (e.g. timings, distribution) during the stage of maturation

\begin{tabular}{|c|c|c|c|c|c|}
\hline Model specification & $\begin{array}{l}\text { Model significance } \\
\left(L R T: \chi^{2}, d f, p\right)\end{array}$ & Variable & Estimate $\pm S E$ & Statistics and $p$-value & Sample size \\
\hline \multicolumn{6}{|c|}{ Southern Africa non-breeding destinations } \\
\hline \multicolumn{6}{|c|}{ M1:(LMM) log10 (Duration post-breeding migration) } \\
\hline Model (intercept) versus & $(4.1,1,0.04)$ & age & $-0.076 \pm 0.033$ & $t=-2.31,0.037$ & 49 \\
\hline Model (age) & & 1:Individual & & $L R T: \chi^{2}=3.09,1,0.08$ & \\
\hline
\end{tabular}

M2: (LMM) Departure date non-breeding ground

Model (intercept) versus $\quad(51.8,1,<0.0001)$
Model (age)

Model poly (age, 1$)$ versus $\quad(6.003,1,0.01)$

Model poly (age, 2)

$(6.003,1,0.01)$

poly (age, 1)

poly (age, 2)

$-118.2 \pm 12$

$t=-9.86, p<0.00001$

50

1:Individual

$29.57 \pm 12$

$t=-2.47, p=0.027$

LRT: $\chi^{2}<0.0001,1,0.99$

M3: (LMM) Duration non-breeding period

Model (intercept) versus

(33.1, 1, <0.0001)

poly (age, 1)

$-99.4 \pm 12.6$

$t=-7.90, p<0.00001$

50

Model (age)

Model poly (age, 1) versus

$(11.8,1,<0.0001)$

poly (age, 2)

$45.6 \pm 12.9$

$t=-3.54, p=0.0033$

1:Individual

$L R T: \chi^{2}=3.5,1,0.06$

M4: (LMM) Arrival date at colony

Model (intercept) versus $\quad(63.0,1,<0.0001)$

Model (age)

Model poly (age, 1 ) versus

Model poly (age, 2)

$(13.8,1,0.001)$

poly (age, 1)

$-158.3 \pm 11.8$

$t=-13.43, p<0.00001$

49

poly (age, 2)

$50.04 \pm 12.3$

$t=-4.08, p=0.0013$

1:Individual

LRT: $\chi^{2}=0.31,1,0.58$

M5: (LMM) log (Arrival date nest)

Model (intercept) versus

Model (age)

$(20.3,1,<0.0001)$

age

$16.74 \pm 3.04$

$t=-5.51, p=0.0053$

1:Individual

LRT $<0.0001,1,0.99$

M6: (LMM) log (Duration pre-breeding migration)

Model (intercept) versus

$(11.3,1,<0.0001)$

Model (age)

age

$-0.13 \pm 0.04$

$t=-3.50, p=0.0036$

49

M7: (LMM) log10 (Number non-breeding areas)
Model (intercept) versus
$(6.8,1,0.009)$
Model (age classes ${ }^{\mathrm{a}}$ )

1:Individual

LRT: $\chi^{2}<0.0001,1,0.98$

M8: (LMM) log (Year-round travelled distance)

Model (intercept) versus $\quad(4.44,1,0.035)$
Model (breeding status $\left.{ }^{b}\right)$

age (7-9 years)

1:Individual

breeding status:

adults

1:Individual $t=-2.9, p=0.01$

LRT: $\chi^{2}=0.59,1,0.44$

$-0.13 \pm 0.04$

$t=-2.11, p=0.03$

$50+77^{c}$

LRT: $\chi^{2}=11.7,1$,

$<0.0001$

50

M9: (LMM) log (Non-breeding period travelled distance)

Model (intercept) versus
Model (breeding status ${ }^{b}$ )

(4.8, 1, 0.029) breeding status: adult

1:Individual
$-0.14 \pm 0.06$

(

All non-breeding destinations

M10: (GLM) Probability first breeding

Model (age + arrival date

$(0.04,1,0.82)$

age

$t=-2.19, p=0.03$

$50+77^{c}$

colony) versus Model (ar-

rival time colony)

Model (age + arrival date

$(5.0,1,0.02)$

arrival date colony

$-0.14 \pm 0.06$

LRT: $\chi^{2}=9.1,1,0.0025$ colony) versus Model (age)

$-0.101 \pm 0.005$

$z=-1.98, p=0.046$ 
TABLE 2 (Continued)

\begin{tabular}{|c|c|c|c|c|c|}
\hline Model specification & $\begin{array}{l}\text { Model significance } \\
\left(\text { LRT: } \chi^{2}, d f, p\right)\end{array}$ & Variable & Estimate $\pm S E$ & Statistics and $p$-value & Sample size \\
\hline \multicolumn{6}{|c|}{ M11: (GLM) Probability using NW-Atlantic } \\
\hline \multicolumn{6}{|c|}{ M12: (LMM) Div. Distribution Index (DI) } \\
\hline \multicolumn{6}{|c|}{ M13: (LMM) Post-breeding migration speed } \\
\hline \multirow{2}{*}{$\begin{array}{l}\text { Model (intercept) versus } \\
\text { Model (age + departure } \\
\text { Canary Current) }\end{array}$} & $(4.3,1,0.039)$ & age & $-0.196 \pm 0.093$ & $t=-2.09, p=0.055$ & \multirow[t]{2}{*}{56} \\
\hline & $(27.1,1,<0.0001)$ & $\begin{array}{l}\text { departure Canary } \\
\text { Current }\end{array}$ & $0.021 \pm 0.003$ & $t=-5.91, p<0.0001$ & \\
\hline
\end{tabular}

Note: Only models including predictors selected by means likelihood ratio test $(L R T)$ are presented. Estimated $\pm S E$, random effects and sample size (number of migratory journeys), are also shown. The effect of age as an explanatory variable was preferentially explored as a polynomial function up to the quadratic order (poly, 2; see Data analysis).

${ }^{a}$ Age classes: 4- to 6-year-old and 7- to 9-year-old immatures.

${ }^{\text {b}}$ Breeding status: immature versus breeding adult.

'Immatures' journeys + adult breeders' journeys.

${ }^{\mathrm{d} O n e}$ trip per bird.

MAIN NON-BREEDING DESTINATIONS

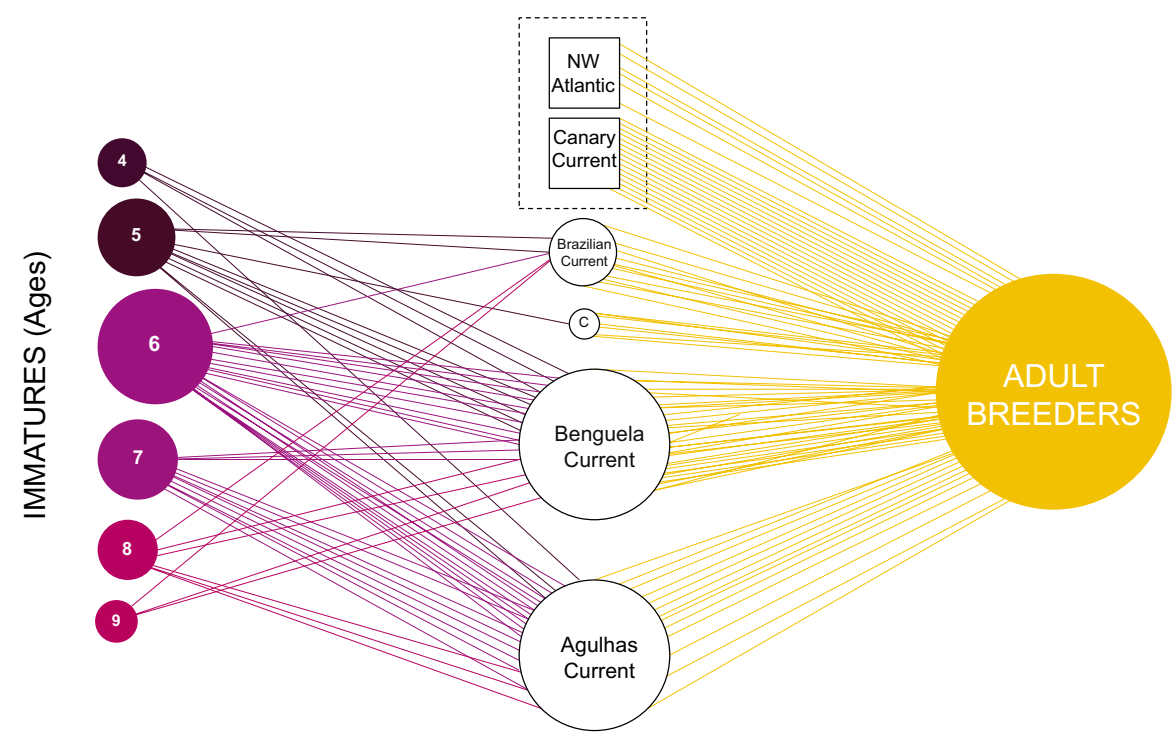

FIG URE 3 Migration flows of Cory's shearwaters from Selvagem Grande to their main non-breeding destinations. Immature group has been split into different age classes (number of journeys 4 years: $n=4 ; 5$ years: $n=10 ; 6$ years: $n=22 ; 7$ years: $n=11 ; 8$ years: $n=6 ; 9$ years: $n=3$ ), whereas adult breeders $(n=108$ ) are shown as one group (bubble area of both is proportional to the number of sampled individuals).

The main non-breeding destinations (e.g. Central Atlantic area; C) are shown as bubbles whose area is proportional to the number of immatures migrating to each region. In the Northern Hemisphere (dotted square), the North-West Atlantic is only used by immatures as a stopover site

This study does not include the migratory behaviour of young shearwaters from fledging to the age of 3 years. Although we have started to collect those data, we do not currently have a sufficient dataset to test this learning and refinement hypothesis for this age class, but the first tracks obtained seem to support this hypothesis (authors, unpublished data). At 4 years old, and after, individuals seem to have already become familiar with the main migratory routes and destinations of this study population, and hence broadly use the same ones as older immatures and adults (with small differences; see below, Figure 1b). In contrast, the migratory schedules of 4- to 5-year-old animals differ markedly from those of breeding adults, becoming progressively adult-like as birds age until reaching the time of first breeding. By this time, their migratory timings and destinations resemble those of breeding adults (Figure 1a). Therefore, our 

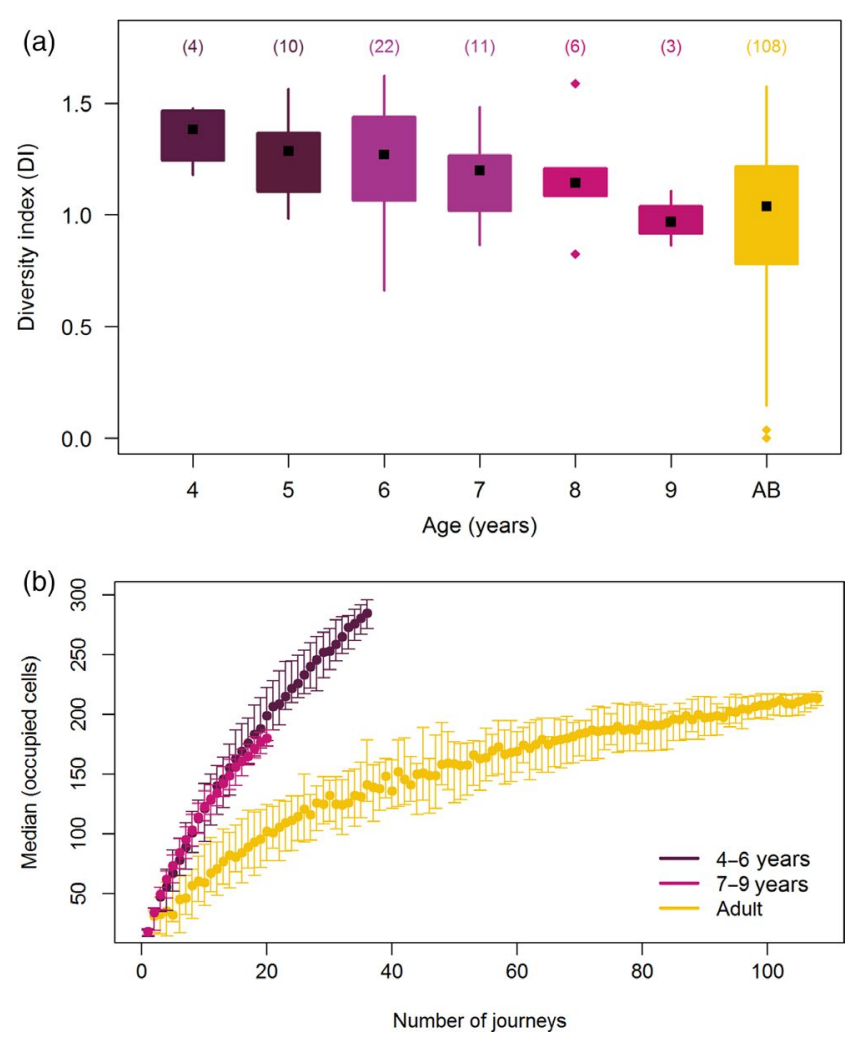

FIGURE 4 (a) Boxplot showing the decrease in spatial diversity distribution (y-axis: $D I$ ) of breeding adults $(A B)$ and immature shearwaters as they progressively mature ( $x$-axis: Age and $A B)$. $D I$ is an index adapted from the Shannon-Wiener index, and it represents an estimate of spatial diversity in the (annual) distribution of individuals over six oceanic regions identified as the main Cory's shearwater's non-breeding areas (see Figure S3). The total data range, the $25 \%$ and $75 \%$ quartiles (box), the median values (black point), the outliers (coloured points) and sample size (in parentheses) are presented. A minimum number of 130 days of tracking per year and individual was set as the threshold to include a bird in the analysis (see Materials and methods for details). (b) The plot compares the spatial extent of the summer distribution (between July and September) of 4- to 6-year-old immature (number of journeys: $4-6$ years, $n=36$ ) and 7- to 9-yearold immature (7-9 years, $n=20$ ) Cory's shearwaters with those of breeding adults (Adult, $n=108$ ). The plot shows how at equal sample sizes immatures of both age groups occupy a larger number of cells (median $\pm 95 \% \mathrm{Cl}$ ). In fact, whereas breeders' cell number (yellow line) seems to stabilize when approaching the maximum sample size $(N=108)$, the median values of 4 - to 6-year-old immature (purple line) and 7- to 9-year-old immature (pink line) shearwaters increase steeply above the values of breeding adults with no sign of a stabilizing trend. For the sake of simplicity: larger median values correspond to wider spatial distributions of birds

results support the hypothesis that in Cory's shearwater, there is a progressive change of migratory strategies mediated by age and experience. Changes in behaviour allow for temporal and spatial refinements of migratory schedules, stopovers and destinations, suggesting that the ontogeny of migratory strategy in long-lived species is a complex and dynamic process that does not stabilize in a fixed migratory strategy after only one or two migratory journeys as proposed for various avian taxa (Boere \& Stroud, 2006; Cresswell, 2014; McKinnon, Fraser, Stanley, \& Stutchbury, 2014).

The progressive changes in spring migration phenology (Figure $2 a-d$ ) shown by our cross-sectional and longitudinal data suggest that age-related variations in such migratory components are prompted by continuous individual improvements in the capability of adjusting the migratory schedule and of travelling in a more direct way (reducing travelling distance), rather than augmenting average speed of travel. Honing the capacity of adjusting internalclock mechanisms and responding to environmental cues before approaching the age of first reproduction is crucial to face to the multiple timing challenges imposed by long migrations, while successfully fitting the necessary activities into an annual cycle. The decrease in migration distance implies that immatures presumably improved their navigational abilities and spatial learning as they get older, which resulted in a gradual optimization of migratory routes (Figure S4A), use of stopovers (Figure 2f) and travel time (Table 1; Figure 2e; Figure S4). Similar results have been observed in other long-lived, long-distance migrants as the black kite (Milvus migrans) or the honey buzzard (Pernis apivorus) where the capacity to use winds or to increase the speed of migration are tuned rapidly in the first years of life (Hake, Kjellén, \& Alerstam, 2003; Sergio et al., 2014) while navigational skills enabling individuals to use optimal routes seem to require several years before being acquired (Berdahl et al., 2018; Mueller, O'Hara, Converse, Urbanek, \& Fagan, 2013; Sergio et al., 2014).

There are consistent across-avian taxa observations of younger birds arriving later to the breeding grounds than older individuals (Hockey, Turpie, Velasquez, \& FitzPatrick, 1998; McKinnon et al., 2014; Sirot \& Touzalin, 2014). In many long-distance migratory species, the shift from "late" to "early" spring migration strategy occurs at the individual level between the first and second spring migration (McKinnon et al., 2014). In contrast, we showed that Cory's shearwaters, similarly to other long-lived species (Sergio et al., 2014), can take years up to 9 years to complete this transition. An alternative explanation to the "exploration-refinement" hypothesis suggests that the "later" spring migration of younger migrants might be evolved as an adaptive strategy (as opposed to a condition-dependent or an ability-dependent strategy) to avoid competition (Kokko, 1999) with experienced (McKinnon et al., 2014) and dominant adults (Francis \& Cooke, 1990). Such a hypothesis could also apply to our study species where the spatial segregation between subdominant immatures and experienced adults is maintained throughout a large part of the breeding season (Figure $1 \mathrm{~b}$ ).

Regardless of the strategy used to return early to the breeding grounds, spring migration is believed to be time-selected to a higher degree than autumn migration, with early arrival increasing the probability to attempt and breed successfully (Bejarano \& Jahn, 2018; Kokko, 1999; Smith \& Moore, 2005). The Cory's shearwater is no exception to this (Catry, Dias, Phillips, \& Granadeiro, 2013). In fact, first-time breeders (of any age) arrived significantly earlier at the colony than conspecifics equal in age that did not recruit, indicating that recruits can have a selective advantage in arriving early. 
In general, when in the natal region, non-breeding immature birds attend the colony during brief visits interspersed with foraging trips at sea. They spend time ashore socializing in the evening/night. Younger birds usually do not own a burrow or a potential nest site where they spend any length of time, while older birds may have acquired a burrow allowing them to be present in the colony during the day. The progressive advancement of colony arrival date with age may help establish partnerships or secure nest sites for future breeding.

Ageing immature birds also showed remarkable changes in the length of stay and departure times from the non-breeding grounds up to synchronizing their schedule with those of breeding adults (Figure 2a,c). How birds keep track of the time spent in the nonbreeding quarters and know when it is time to leave is likely linked to the interplay between internal-clock mechanisms and the ability to track environmental conditions across the annual cycle (Åkesson et al., 2017; Kramer, 1957). Moreover, the temporal mismatch of at least 1 month (see Table 1 and Figure 2a,b) in the spring migration timings between adults and 4- to 5-year-old immatures suggests that younger generations are not relying on the cultural transmission of migration-route choices from adult individuals. This does not exclude that in shearwaters, social transmission of knowledge might be taking place along different age classes with younger individuals copying or learning from older conspecifics closer in age. In some long-lived and long-distance migrants, such as storks and cranes, innate capacities alone are not sufficient to develop migratory behaviour and social learning from older individuals is crucial (Mueller et al., 2013; Rotics et al., 2016). Moreover, in Cory's shearwater, cultural transmission cannot yet be ruled out as the departure dates from colony of fledglings and adults may show a substantial overlap. However, preliminary data currently being collected on fledglings' migration movements suggest that they are not following adult individuals.

Breeding adult and immature shearwaters overlapped extensively in their southern destinations, but only adult breeders extensively used the Canary Current and the North-West Atlantic as a wintering destination (Figure 3). Previous works highlighted significant reproductive benefits (i.e. more chances to breed) for adult shearwaters that reduce migration distance by remaining sedentary in the Canary Current and are consequently able to arrive earlier to their nesting sites the following spring (Catry et al., 2013; Pérez et al., 2013). Following this reasoning, compared to immatures, breeders have a greater incentive to stay in the Northern Hemisphere and endure the boreal winter while remaining close to the natal areas. Despite this, in the winter preceding recruitment, none of our birds chose to overwinter in the Northern Hemisphere, suggesting a trade-off between migration distance and the quality of the wintering site and that wintering in proximity to the breeding grounds may not be the best option for younger or less experienced individuals.

The diversity of use of various oceanic domains declined as the birds aged (DI; Figure 4a) suggesting a behavioural transition from a more explorative strategy in younger individuals to a more conservative way of exploiting resources typical of more experienced individuals. Active exploratory movements often observed in the youngest age classes (Campioni, Granadeiro, \& Catry, 2017; Orben et al., 2018; Péron \& Grémillet, 2013; Riotte-Lambert \& Weimerskirch, 2013) may promote individual learning, a process that in long-lived species allows individuals to make a diversity of choices concerning strategies to be used later in life. Surprisingly, perhaps, this exploration did not translate into a lower repeatability in the choice of the main wintering areas when compared to adults. Adults in this species are generally site-faithful, but show regular shifts in wintering areas whose drivers are still largely unknown (Dias et al., 2011). It is possible that by 4 years of life, our immature shearwaters had already explored enough to become familiar with the various wintering areas available and had made their main choices.

During the breeding season, the spatial distribution of breeding adults was concentrated in the Canary Current area while immatures were more widely spaced out in the North Atlantic (Figures $1 \mathrm{~b}$ and $4 \mathrm{~b}$ ). At this stage, adults are highly constrained by the need to frequently attend the nest site, while immatures are free to roam and explore as well as to potentially select areas where they can avoid competition from breeding conspecifics. Such competition is likely intense in the Canary Current, where adults from various large colonies regularly forage (Ramos et al., 2013). Evidence for spatial and/or trophic segregation between adult and immature individuals during the breeding season has recently been reported in Cory's shearwaters and other long-lived top predators (Campioni, Granadeiro, \& Catry, 2016; Fayet et al., 2015; Jaeger et al., 2014; Votier, Grecian, Patrick, \& Newton, 2011).

To conclude, the present work provides new and missing information on the ontogeny of migratory strategy in long-lived species (but see Sergio et al., 2014; Weimerskirch et al., 2014). We outlined here that the refinement of migratory behaviour and year-round spatial distribution of shearwaters is a gradual and prolonged process mediated by age and experience, which may even persist throughout an animal's life. Nevertheless, life stage-specific constraints and competition for resources also seem to play a role.

\section{ACKNOWLEDGEMENTS}

We are grateful to T. Catry, H. Alonso, F. Gervasio and the numerous people who helped in data collection. We are also grateful to the handling editor Annette Fayet, two anonymous referees and an associated editor for their helpful comments that substantially improved the manuscript. All work was approved by the relevant authorities: Instituto da Conservação da Natureza e das Florestas and Instituto das Florestas e da Conservação da Natureza (Madeira), which provided annual research permits including animal manipulation and ringing during the whole study period. Particularly, we are grateful to wardens, D. Menezes, P. Oliveira and C.S. Jardim, who made fieldwork on the Selvagens possible. This study was supported by Fundação para a Ciência e a Tecnologia (FCT) through the grant awarded to L.C. (FCT-SFRH/BPD/89904/2012). Moreover, Fundação para a Ciência e a Tecnologia (FCT Portugal) provided financial support 
through the strategic project UID/MAR/04292/2013 granted to MARE and the projects IF/00502/2013/CP1186/CT0003 and PTDC/BIA-ANM/3743/2014, UID/AMB/50017 to CESAM (with cofunding by FEDER, within the PT2020 Partnership Agreement and Compete 2020) and PTDC/MAR-PRO/0929/2014.

\section{AUTHORS' CONTRIBUTIONS}

P.C. and J.P.G. conceived the study; M.P.D., L.C., J.P.G. and P.C. collected field data; M.P.D. and L.C. processed and analysed the data; L.C. and J.P.G. carried out the statistical analyses; L.C. participated in the design of the study and with P.C. drafted the manuscript; J.P.G. and M.P.D. helped draft the manuscript; and all authors provide critical review and gave final approval for publication.

\section{DATA AVAILABILITY STATEMENT}

Data available from the seabirdtracking Dryad Digital Repository: http://www.seabirdtracking.org/mapper/contributor.php?contr ibutor_xml:id=68

\section{ORCID}

Letizia Campioni (iD https://orcid.org/0000-0002-6319-6931

Maria Peixe Dias (iD https://orcid.org/0000-0002-7281-4391

José Pedro Granadeiro (iD https://orcid.org/0000-0002-7207-3474

Paulo Catry iD https://orcid.org/0000-0003-3000-0522

\section{REFERENCES}

Åkesson, S., Ilieva, M., Karagicheva, J., Rakhimberdiev, E., Tomotani, B., $\&$ Helm, B. (2017). Timing avian long-distance migration: From internal clock mechanisms to global flights. Philosophical Transactions of the Royal Society B: Biological Sciences, 372, 20160252. https://doi. org/10.1098/rstb.2016.0252

Alerstam, T., Hedenstrom, A., \& Akesson, S. (2003). Long-distance migration: Evolution and determinants. Oikos, 103, 247-260. https://doi. org/10.1034/j.1600-0706.2003.12559.x

Bejarano, V., \& Jahn, A. E. (2018). Relationship between arrival timing and breeding success of intra-tropical migratory Fork-tailed Flycatchers (Tyrannus savana). Journal of Field Ornithology, 89, 109-116. https:// doi.org/10.1111/jofo.12251

Berdahl, A. M., Kao, A. B., Flack, A., Westley, P. A. H., Codling, E. A., Couzin, I. D., ... Biro, D. (2018). Collective animal navigation and migratory culture: From theoretical models to empirical evidence. Philosophical Transactions Royal Society B, 373, 20170009. https://doi. org/10.1098/rstb.2017.0009

Boere, G. C., \& Stroud, D. A. (2006). The flyway concept: What it is and what it isn't. In G. C. Boere, C. A. Galbraith, \& D. A. Stroud (Eds.), Waterbirds around the world (pp. 40-47). Edinburgh, UK: The Stationery Office.

Breed, G. A., Bowen, W. D., \& Leonard, L. (2013). Behavioral signature of intraspecific competition and density dependence in colony-breeding marine predators. Ecology and Evolution, 3, 3838-3854. https:// doi.org/10.1002/ece3.754

Brown, C. R., Bomberger Brown, M., \& Brazeal, K. R. (2008). Familiarity with breeding habitat improves daily survival in colonial cliff swallows.
Animal Behaviour, 76, 1201-1210. https://doi.org/10.1016/j.anbeh av.2008.03.028

Campioni, L., Granadeiro, J. P., \& Catry, P. (2016). Niche segregation between immature and adult seabirds: Does progressive maturation play a role? Behavioral Ecology, 27, 426-433. https://doi.org/10.1093/ beheco/arv167

Campioni, L., Granadeiro, J. P., \& Catry, P. (2017). Albatrosses prospect before choosing a home: Intrinsic and extrinsic sources of variability in visit rates. Animal Behaviour, 128, 85-93. https://doi.org/10.1016/j. anbehav.2017.04.008

Carravieri, A., Weimerskirch, H., Bustamante, P., \& Cherel, Y. (2017). Progressive ontogenetic niche shift over the prolonged immaturity period of wandering albatrosses. Royal Society Open Science, 4, 171039. https://doi.org/10.1098/rsos.171039

Catry, P., Dias, M. P., Phillips, R. A., \& Granadeiro, J. P. (2013). Carry-over effects from breeding modulate the annual cycle of a long-distance migrant: An experimental demonstration. Ecology, 94, 1230-1235. https://doi.org/10.1890/12-2177.1

Clutton-Brock, T. H. (1988). Reproductive success. Studies of individual variation in contrasting breeding systems. Chicago, IL: University of Chicago Press.

Cresswell, W. (2014). Migratory connectivity of Palaearctic-African migratory birds and their responses to environmental change: The serial residency hypothesis. Ibis, 156, 493-510. https://doi.org/10.1111/ ibi.12168

Daunt, F., Afanasyev, V., Adam, A., Croxall, J. P., \& Wanless, S. (2007). From cradle to early grave: Juvenile mortality in European shags Phalacrocorax aristotelis results from inadequate development of foraging proficiency. Biology Letters, 3, 371-374. https://doi. org/10.1098/rsbl.2007.0157

de Grissac, S., Börger, L., Guitteaud, A., \& Weimerskirch, H. (2016). Contrasting movement strategies among juvenile albatrosses and petrels. Scientific Reports, 6, 26103. https://doi.org/10.1038/srep2 6103

Dell' Ariccia, G., Benhamou, S., Dias, M. P., Granadeiro, J. P., Sudre, J., Catry, P., \& Bonadonna, F. (2018). Flexible migratory choices of Cory's shearwaters are not driven by shifts in prevailing air currents. Scientific Reports, 8, 3376. https://doi.org/10.1038/ s41598-018-21608-2

Dias, M. P., Granadeiro, J. P., \& Catry, P. (2012). Do seabirds differ from other migrants in their travel arrangements? On route strategies of Cory's shearwater during its trans-equatorial journey. PLOS ONE, 7, e49376. https://doi.org/10.1371/journal.pone.0049376

Dias, M. P., Granadeiro, J. P., \& Catry, P. (2013). Individual variability in the migratory path and stopovers of a long-distance pelagic migrant. Animal Behaviour, 86, 359-364. https://doi.org/10.1016/j.anbeh av.2013.05.026

Dias, M. P., Granadeiro, J. P., Phillips, R. A., Alonso, H., \& Catry, P. (2011). Breaking the routine: Individual Cory's shearwaters shift winter destinations between hemispheres and across ocean basins. Proceedings of the Royal Society B: Biological Sciences, 278, 1786-1793. https://doi. org/10.1098/rspb.2010.2114

Dukas, R. (2004). Evolutionary biology of animal cognition. Annual Review of Ecology Evolution and Systematics, 35, 347-374. https://doi. org/10.1146/annurev.ecolsys.35.112202.130152

Fagan, W. F., Lewis, M. A., Auger-Méthé, M., Avgar, T., Benhamou, S., Breed, G., ... Mueller, T. (2013). Spatial memory and animal movement. Ecology Letters, 16, 1316-1329. https://doi.org/10.1111/ ele.12165

Faraway, J. J. (2006). Extending the linear model with R. Generalized linear, mixed effects and nonparametric regression models. Boca Raton, FL: Chapman and Hall/CRC.

Fayet, A. L., Freeman, R., Anker-Nilssen, T., Diamond, A., Erikstad, K. E., Fifield, D., ... Guilford, T. (2017). Ocean-wide drivers of migration strategies and their influence on population breeding performance 
in a declining seabird. Current Biology, 7, 3871-3878.e3. https://doi. org/10.1016/j.cub.2017.11.009

Fayet, A. L., Freeman, R., Shoji, A., Padget, O., Perrins, C. M., \& Guilford, T. (2015). Lower foraging efficiency in immatures drives spatial segregation with breeding adults in a long-lived pelagic seabird. Animal Behaviour, 110, 79-89. https://doi.org/10.1016/j.anbeh av.2015.09.008

Forslund, P., \& Pärt, T. (1995). Age and reproduction in birds-hypotheses and tests. Trends in Ecology and Evolution, 10, 364-378. https://doi. org/10.1016/S0169-5347(00)89141-7

Francis, C. M., \& Cooke, C. F. (1990). Differential timing of spring migration in Rose-breasted Grosbeaks. Journal of Field Ornithology, 61, 404-412.

González-Solís, J., Croxall, J., Oro, D., \& Ruiz, X. (2007). Trans-equatorial migration and mixing in the wintering areas of a pelagic seabird. Frontiers in Ecology and the Environment, 5, 297-301. https://doi. org/10.1890/15409295(2007)5[297:TMAMIT]2.0.CO;2

Granadeiro, J. P. (1993). Variation in measurements of Cory's shearwater between populations and sexing by discriminant analysis. Ringing and Migration, 14, 103-112. https://doi.org/10.1080/03078 698.1993.9674051

Granadeiro, J. P., Dias, M. P., Rebelo, R., Santos, C. D., \& Catry, P. (2006). Numbers and population trends of Cory's shearwater Calonectris diomedea at Selvagem Grande, northeast Atlantic. Waterbirds, 29, 56-60. https://doi.org/10.1675/1524-4695(2006)29[56:NAPTO C]2.0.CO;2

Griffiths, R., Double, M., Orr, K., \& Dawson, R. (1998). A simple DNA test to sex most birds. Molecular Ecology, 7, 1071-1076. https://doi. org/10.1046/j.1365-294x.1998.00389.x

Guilford, T., Freeman, R., Boyle, D., Dean, B., Kirk, H., Phillips, R., \& Perrins, C. (2011). A dispersive migration in the Atlantic puffin and its implications for migratory navigation. PLoS ONE, 6, e21336. https:// doi.org/10.1371/journal.pone.0021336

Hake, M., Kjellén, N., \& Alerstam, T. (2003). Age-Dependent Migration Strategy in Honey Buzzards Pernis apivorus Tracked by Satellite. Oikos, 103, 385-396. https://doi.org/10.1034/j.1600-0706.2003.12145.x

Hays, G. C., Fossette, S., Katselidis, K. A., Mariani, P., \& Schofield, G. (2010). Ontogenetic development of migration: Lagrangian drift trajectories suggest a new paradigm for sea turtles. Journal of the Royal Society Interface, 7, 1319-1327. https://doi.org/10.1098/ rsif.2010.0009

Hockey, P. A. R., Turpie, J. K., Velasquez, C. R., \& FitzPatrick, P. (1998). What selective pressures have driven the evolution of deferred northwards migration by juvenile waders? Journal Avian Biology, 29, 325-330. https://doi.org/10.2307/3677117

Jaeger, A., Goutte, A., Lecomte, V. J., Richard, P., Chastel, O., Barbraud, C., ... Cherel, Y. (2014). Age, sex, and breeding status shape a complex foraging pattern in an extremely long-lived seabird. Ecology, 95, 2324-2333. https://doi.org/10.1890/13-1376.1

Kokko, H. (1999). Competition for early arrival in migratory birds. Journal of Animal Ecology, 68, 940-950. https://doi. org/10.1046/j.1365-2656.1999.00343.x

Kramer, G. (1957). Experiments on bird orientation and their interpretation. Ibis, 99, 196-227. https://doi.org/10.1111/j.1474-919X.1957. tb01947.x

Lamb, J. S., Satgé, Y. G., \& Jodice, P. G. R. (2017). Influence of density-dependent competition on foraging and migratory behavior of a subtropical colonial seabird. Ecology and Evolution, 7, 6469-6481. https ://doi.org/10.1002/ece3.3216

Le Vaillant, M., Wilson, R. P., Kato, A., Saraux, C., Hanuise, N., Prud'Homme, O., ... Ropert-Coudert, Y. (2012). King penguins adjust their diving behaviour with age. Journal of Experimental Biology, 215, 3685-3692. https://doi.org/10.1242/jeb.071175

Lecomte, V. J., Sorci, G., Cornet, S., Jaeger, A., Faivre, B., Arnoux, E., ... Weimerskirch, H. (2010). Patterns of aging in the long-lived wandering albatross. Proceedings of the National Academy of Sciences of the United States of America, 107, 6370-6375. https://doi. org/10.1073/pnas.0911181107

Lefebvre, L. (1995). Culturally-transmitted feeding-behavior in primatesevidence for accelerating learning rates. Primates, 36, 227-239. https ://doi.org/10.1007/BF02381348

McKinnon, E. A., Fraser, K. C., Stanley, C. Q., \& Stutchbury, B. J. M. (2014). Tracking from the tropics reveals behaviour of juvenile songbirds on their first spring migration. PLOS ONE, 9, e105605. https:// doi.org/10.1371/journal.pone.0105605

Mettke-Hofmann, C., \& Gwinner, E. (2003). Long-term memory for a life on the move. Proceedings of the National Academy of Sciences of the United States of America, 100, 5863-5866. https://doi.org/10.1073/ pnas. 1037505100

Mougin, J.-L., Jouanin, C., \& Roux, F. (2000). Démographie du puffin cendré Calonectris diomedea de Selvagem Grande. Revue D' Écologie (Terre Vie), 55, 275-290.

Mueller, T., O'Hara, R. B., Converse, S. J., Urbanek, R. P., \& Fagan, W. F. (2013). Social Learning of migratory performance. Science, 341, 999-1002. https://doi.org/10.1126/science.1237139

Newton, I. (1989). Lifetime reproduction in birds. London, UK: Academic Press.

Orben, R. A., O'Connor, A. J., Suryan, R. M., Ozaki, K., Sato, F., \& Deguchi, T. (2018). Ontogenetic changes in at-sea distributions of immature short-tailed albatrosses Phoebastria albatrus. Endangered Species Research, 35, 23-37. https://doi.org/10.3354/esr00864

Pärt, T. (1995). Does breeding experience explain increased reproductive success with age? An experiment. Proceedings of the Royal Society B: Biological Sciences, 260, 113-117. https://doi.org/10.1098/ rspb.1995.0067

Penteriani, V., Delgado, M. M., \& Campioni, L. (2015). Quantifying space use of breeders and floaters of a long-lived species using individual movement data. The Science of Nature, 102, 21. https://doi. org/10.1007/s00114-015-1271-x

Pérez, C., Granadeiro, J. P., Dias, M. P., Alonso, H., \& Catry, P. (2013). When males are more inclined to stay at home: Insights into the partial migration of a pelagic seabird provided by geolocators and isotopes. Behavioral Ecology, 25, 313-319. https://doi.org/10.1093/ beheco/art119

Péron, C., \& Grémillet, D. (2013). Tracking through life stages: Adult, immature and juvenile autumn migration in a long-lived seabird. PLoS ONE, 8, e72713. https://doi.org/10.1371/journal.pone.0072713

Phillips, R., Silk, J., Croxall, J., Afanasyev, V., \& Briggs, D. (2004). Accuracy of geolocation estimates for flying seabirds. Marine Ecology Progress Series, 266, 265-272. https://doi.org/10.3354/meps266265

R Core Team (2016). R: A language and environment for statistical computing. Vienna, Austria: R Foundation for Statistical Computing. Retrieved from http://www.R-project.org/

Raine, N. E., \& Chittka, L. (2008). The correlation of learning speed and natural foraging success in bumble-bees. Proceedings of the Royal Society B: Biological Sciences, 275, 803-808. https://doi.org/10.1098/ rspb.2007.1652

Ramos, J., Granadeiro, J. P., Phillips, R., \& Catry, P. (2009). Flight morphology and foraging behaviour of male and female Cory's shearwaters. The Condor, 111, 424-432. https://doi.org/10.1525/ cond.2009.090008

Ramos, R., Granadeiro, J. P., Rodríguez, B., Navarro, J., Paiva, V. H., Bécares, J., ... Catry, P. (2013). Meta-population feeding grounds of Cory's shearwater in the subtropical Atlantic Ocean: Implications for the definition of Marine Protected Areas based on tracking studies. Diversity and Distribution, 19, 1284-1298. https://doi.org/10.1111/ddi.12088

Riotte-Lambert, L., \& Weimerskirch, H. (2013). Do naive juvenile seabirds forage differently from adults? Proceedings of the Royal Society B: Biological Sciences, 280, 20131434. https://doi.org/10.1098/ rspb.2013.1434 
Rotics, S., Kaatz, M., Resheff, Y. S., Turjeman, S. F., Zurell, D., Sapir, N., ... Nathan, R. (2016). The challenges of the first migration: Movement and behaviour of juvenile vs. adult white storks with insights regarding juvenile mortality. Journal of Animal Ecology, 85, 938-947. https:// doi.org/10.1111/1365-2656.12525

Sergio, F., Tanferna, A., De Stephanis, R., Jiménez, L. L., Blas, J., Tavecchia, G., ... Hiraldo, F. (2014). Individual improvements and selective mortality shape lifelong migratory performance. Nature, 515, 410-413. https://doi.org/10.1038/nature13696

Shettleworth, S. J. (1999). Cognition, evolution, and behavior. Oxford, UK: Oxford University Press.

Sirot, E., \& Touzalin, F. (2014). Temporal patterns of arrival from migration as a response to competition for breeding space. Journal Avian Biology, 45, 109-112. https://doi.org/10.1111/j.1600-048X.2013.00184.x

Smith, R. J., \& Moore, F. R. (2005). Arrival timing and seasonal reproductive performance in a long-distance migratory landbird. Behavioral Ecology and Sociobiology, 57, 231-239. https://doi.org/10.1007/ s00265-004-0855-9

Strandberg, R., Klaassen, R., Hake, M., Olofsson, P., Thorup, K., \& Alerstam, T. (2008). Complex timing of Marsh Harrier Circus aeroginosus migration due to pre- and post-migratory movements. Ardea, 96, 159-217. https://doi.org/10.5253/078.096.0202

Thibault, J.-C., Bretagnolle, V., \& Rabouam, C. (1997). Calonectris diomedea Cory's shearwater. BWP Update, 1, 75-98.

Thiebot, J.-B., Cherel, Y., Trathan, P. N., \& Bost, C.-A. (2012). Coexistence of oceanic predators on wintering areas explained by populationscale foraging segregation in space or time. Ecology, 93, 122-130. https://doi.org/10.1890/11-0385.1

Thorup, K., Alerstam, T., Hake, M., \& Kjellén, N. (2003). Bird orientation: Compensation for wind drift in migrating raptors is age dependent. Proceedings of the Royal Society B: Biological Sciences, 270, S8-11. https://doi.org/10.1098/rsbl.2003.0014

Vansteelant, W. M. G., Kekkonen, J., \& Byholm, P. (2017). Wind conditions and geography shape the first outbound migration of juvenile honey buzzards and their distribution across sub-Saharan Africa. Proceedings of the Royal Society B: Biological Sciences, 284, 20170387. https://doi.org/10.1098/rspb.2017.0387

Vardanis, Y., Klaassen, R. H. G., Strandberg, R., \& Alerstam, T. (2011). Individuality in bird migration: Routes and timing. Biology Letters, 7, 502-505. https://doi.org/10.1098/rsbl.2010.1180

Votier, S. C., Fayet, A. L., Bearhop, S., Bodey, T. W., Clark, B. L., Grecian, J., ... Patrick, S. C. (2017). Effects of age and reproductive status on individual foraging site fidelity in a long-lived marine predator. Proceedings of the Royal Society B: Biological Sciences, 284, 20171068. https://doi.org/10.1098/rspb.2017.1068

Votier, S. C., Grecian, W. J., Patrick, S., \& Newton, J. (2011). Inter-colony movements, at sea behaviour and foraging in an immature seabird: Results from GPS-PTT tracking, radio-tracking and stable isotope analysis. Marine Biology, 158(2), 355-362. https://doi.org/10.1007/ s00227-010-1563-9
Wakefield, E. D., Cleasby, I. R., Bearhop, S., Bodey, T. W., Davies, R. D., Miller, P. I., ... Hamer, K. C. (2015). Long-term individual foraging site fidelity-Why some gannets don't change their spots. Ecology, 96, 3058-3074. https://doi.org/10.1890/14-1300.1

Webb, W. C., Marzluff, J. M., \& Hepinstall-Cymerman, J. (2012). Differences in space use by common ravens in relation to sex, breeding status, and kinship. The Condor, 114, 584-594. https://doi. org/10.1525/cond.2012.110116

Weimerskirch, H., Cherel, Y., Delord, K., Jaeger, A., Patrick, S. C., \& RiotteLambert, L. (2014). Lifetime foraging patterns of the wandering albatross: Life on the move!. Journal of Experimental Marine Biology and Ecology, 450, 68-78. https://doi.org/10.1016/j.jembe.2013.10.021

Yamamoto, T., Takahashi, A., Sato, K., Oka, N., Yamamoto, M., \& Trathan, P. N. (2014). Individual consistency in migratory behaviour of a pelagic seabird. Behaviour, 151, 683-701. https://doi.org/10.1163/15685 39X-00003163

Yoda, K., Kohno, H., \& Naito, Y. (2004). Development of flight performance in the brown booby. Proceedings of the Royal Society B: Biological Sciences, 271, S240-S242. https://doi.org/10.1098/ rsbl.2003.0157

Yoda, K., Yamamoto, T., Suzuki, H., Matsumoto, S., Müller, M., \& Yamamoto, M. (2017). Compass orientation drives naïve pelagic seabirds to cross mountain ranges. Current Biology, 27, R1152-R1153. https://doi.org/10.1016/j.cub.2017.09.009

Zimmer, I., Ropert-Coudert, Y., Kato, A., Ancel, A., \& Chiaradia, A. (2011). Does foraging performance change with age in female little penguins (Eudyptula minor)? PLoS ONE, 6, e16098. https://doi.org/10.1371/ journal.pone.0016098

Zuur, A. F., leno, E. N., Walker, N. J., Saveliev, A. A., \& Smith, G. M. (2009). Mixed effects models and extensions in ecology with R. New York, NY: Springer.

\section{SUPPORTING INFORMATION}

Additional supporting information may be found online in the Supporting Information section at the end of the article.

How to cite this article: Campioni L, Dias MP, Granadeiro JP, Catry P. An ontogenetic perspective on migratory strategy of a long-lived pelagic seabird: Timings and destinations change progressively during maturation. J Anim Ecol. 2020;89:29-43. https://doi.org/10.1111/1365-2656.13044 